\title{
Follow-Up After Curative Cancer Surgery: Understanding Costs and Benefits
}

\author{
Bridget N. Fahy, MD \\ Department of Surgery, UNM Cancer Center, University of New Mexico, Albuquerque, NM
}

According to the American Cancer Society, well over 1 million new cancer patients are added each year to the 13.7 million alive today. ${ }^{1}$ Consequently, the field of cancer survivorship has become the focus of an increasing amount of attention for both patients and their cancer care providers. In 2005, the Institute of Medicine published a report on cancer survivorship and identified surveillance for cancer spread, recurrence, or second cancers as essential components of survivorship care. ${ }^{2}$ As primary providers of cancer treatment, it is imperative that surgeons be active participants in designing and executing survivorship care. To meet this requirement, surgeons must utilize an evidence-based approach to determine how best to follow their patients after curative cancer surgery.

Presumed benefits of follow-up following curative cancer surgery include the following: (i) earlier detection of recurrences that result in increased likelihood of curative intervention, (ii) identification of second primary malignancies, and (iii) patient reassurance. Are any or all of these assumptions true? The answer is: it depends. Factors that impact the potential benefit of follow-up include the location of the primary tumor, stage at initial presentation, availability of effective therapies, and patient desire and fitness for cancer therapy. Additionally, one must consider which test(s) are most likely to identify cancer recurrences amenable to treatment or second primary malignancies and the optimal timing of such testing.

In addition to the presumed benefits of follow-up after curative cancer surgery, there are both financial and non-financial costs to be considered. Chief among the

(C) Society of Surgical Oncology 2013

First Received: 22 October 2013; Published Online: 27 December 2013

B. N. Fahy, MD

e-mail: DrBFahy@yahoo.com non-economic costs of surveillance is the emotional cost of surveillance, which was the focus of a recent editorial by Dr. John Smyth in The ASCO Post. ${ }^{3}$ As Dr. Smyth points out, cancer surveillance is a "balance between what we need to know as physicians and what is best for the individual patient." Dr. Brennan also cautioned in an editorial in Annals of Surgical Oncology that the "need for (patient) reassurance has to be balanced against the anxiety provoked by extensive follow-up testing, such as CT or MRI, which provoke severe distress disorders in the most sanguine of patients." 4

The financial cost of cancer follow-up is another important consideration as clinicians, patients, government, and third-party payors carefully consider the cost effectiveness of various healthcare expenditures. A recent article by Mariotto et al. ${ }^{5}$ estimated the cost of cancer care in the USA from 2010 to 2020 and found that costs for all cancer care across the different phases of care (e.g. diagnosis through last year of life) were projected to increase from \$US124.57 billion in 2010 to \$US186.69 billion in 2020 . Some of the largest projected increases in cancer costs were seen in melanoma (95\%), pancreas (67\%), breast (41\%), and colorectal (25\%) cancer. Given that these are tumors primarily managed by surgical resection, it is incumbent upon surgeons to be good stewards of the financial resources needed to treat and follow these patients following curative cancer surgery.

Optimal surveillance after curative cancer surgery should ideally be based upon knowledge of the risk of cancer recurrence for a given patient, understanding of surveillance techniques most likely to identify recurrence amenable to treatment, and an appreciation of which patients are most likely to benefit from additional cancer therapies. As illustrated above, any follow-up program must also consider both the emotional and financial cost of a given surveillance strategy. Unfortunately, the data needed to inform decisions regarding optimal surveillance following curative resection are not uniformly available. 
In this issue of Annals of Surgical Oncology, a series of review articles have been solicited in which the authors summarize what is currently known about surveillance strategies following curative cancer surgery for breast, colon, pancreas, melanoma, and hepatocellular cancer. For each of these tumor types, the authors have reviewed the current literature regarding the risk of recurrence following curative resection and the various surveillance tools that have been studied to identify recurrences. Available data about the benefit of low- versus high-intensity follow-up is reviewed, where available. Each article concludes with recommendations for surveillance following curative cancer resection based upon the currently available literature.

The growing number of cancer survivors brings with it the challenge of designing and implementing a strategy for follow-up that balances tumor characteristics, patient factors, and economic and non-economic burdens. The authors of the review articles contained herein have attempted to critically review the available data on surveillance for most of the common tumors that surgeons routinely treat in hopes of providing an evidence-based approach to followup after curative cancer surgery.

\section{REFERENCES}

1. American Cancer Society. Cancer treatment and survivorship facts and figures 2012-2013. 2012. Available from: http://www.cancer. org/acs/groups/content/@epidemiologysurveilance/documents/ document/acspc-033876.pdf. Accessed 20 Oct 2013.

2. Institute of Medicine. Educating cancer health providers. 2005. Available from: http://www.iom.edu/ /media/Files/Report\% 20Files/2005/From-Cancer-Patient-to-Cancer-Survivor-Lost-inTransition/factsheeteducation.pdf. Accessed 20 Oct 2013.

3. Smyth JF. The problem of monitoring remission. The ASCO Post. 2012;3(13):1.

4. Brennan MF. Follow-up is valuable and effective: true, true and unrelated? Ann Surg Oncol. 2000;7:2-3.

5. Mariotto AB, Yabroff KR, Shao Y, Feuer EJ, Brown ML. Projections of the cost of cancer care in the United States: 2010-2020. J Natl Cancer Inst. 2011;103:117-128. 